University of Nebraska - Lincoln

DigitalCommons@University of Nebraska - Lincoln

USDA Forest Service / UNL Faculty Publications U.S. Department of Agriculture: Forest Service -National Agroforestry Center

2011

\title{
Heat waves measured with MODIS land surface temperature data predict changes in avian community structure
}

Thomas P. Albright

University of Wisconsin-Madison

Anna M. Pidgeon

University of Wisconsin-Madison

Chadwick D. Rittenhouse

University of Wisconsin-Madison

Murray K. Clayton

University of Wisconsin-Madison, clayton@stat.wisc.edu

Curtis H. Flather

Rocky Mountain Research Station

See next page for additional authors

Follow this and additional works at: https://digitalcommons.unl.edu/usdafsfacpub

Part of the Forest Sciences Commons

Albright, Thomas P.; Pidgeon, Anna M.; Rittenhouse, Chadwick D.; Clayton, Murray K.; Flather, Curtis H.; Culbert, Patrick D.; and Radeloff, Volker C., "Heat waves measured with MODIS land surface temperature data predict changes in avian community structure" (2011). USDA Forest Service / UNL Faculty Publications. 154.

https://digitalcommons.unl.edu/usdafsfacpub/154

This Article is brought to you for free and open access by the U.S. Department of Agriculture: Forest Service -National Agroforestry Center at DigitalCommons@University of Nebraska - Lincoln. It has been accepted for inclusion in USDA Forest Service / UNL Faculty Publications by an authorized administrator of DigitalCommons@University of Nebraska - Lincoln. 


\section{Authors}

Thomas P. Albright, Anna M. Pidgeon, Chadwick D. Rittenhouse, Murray K. Clayton, Curtis H. Flather, Patrick D. Culbert, and Volker C. Radeloff 


\title{
Heat waves measured with MODIS land surface temperature data predict changes in avian community structure
}

\author{
Thomas P. Albright a,*, Anna M. Pidgeon a , Chadwick D. Rittenhouse a , Murray K. Clayton ${ }^{\mathrm{b}}$, Curtis H. Flather ${ }^{\mathrm{c}}$, \\ Patrick D. Culbert ${ }^{a}$, Volker C. Radeloff ${ }^{a}$
}

a Department of Forest and Wildlife Ecology, University of Wisconsin-Madison, WI 53706, USA

${ }^{\mathrm{b}}$ Department of Statistics, University of Wisconsin-Madison, WI 53706, USA

${ }^{c}$ Rocky Mountain Research Station, USDA Forest Service, Fort Collins, CO 80526, USA

\section{A R T I C L E I N F O}

\section{Article history:}

Received 29 April 2010

Received in revised form 24 August 2010

Accepted 28 August 2010

\section{Keywords:}

Abundance

Biodiversity

Birds

Climate change

Heat waves

Land surface temperature

Mixed effects models

MODIS

North American Breeding Bird Survey

PRISM

Species richness

United States

\begin{abstract}
A B S T R A C T
Heat waves are expected to become more frequent and severe as climate changes, with unknown consequences for biodiversity. We sought to identify ecologically-relevant broad-scale indicators of heat waves based on MODIS land surface temperature (LST) and interpolated air temperature data and assess their associations with avian community structure. Specifically, we asked which data source, time periods, and heat wave indices best predicted changes in avian abundance and species richness. Using mixed effects models, we analyzed associations between these indices and data from the North American Breeding Bird Survey in the central United States between 2000 and 2007 in four ecoregions and five migratory and nesting species groups. We then quantified avian responses to scenarios of severe, but commonly-occurring early, late, and summer-long heat waves. Indices based on MODIS LST data, rather than interpolated air temperatures, were more predictive of avian community structure. Avian communities were more related to 8-day LST exceedances (positive anomalies only); and were generally more sensitive to summer-long heat waves. Across the region, abundance, and to a lesser extent, species richness, declined following heat waves. Among the ecoregions, relationships were most consistently negative in the southern and montane ecoregions, but were positive in a more humid northern ecoregion. Among migratory groups, permanent resident species were the most sensitive, declining in abundance following a summer-long heat wave by $19 \%$ and $13 \%$ in the montane and southern ecoregions, respectively. Ground-nesting species, which declined in the south by $12 \%$ following a late summer heat wave, were more sensitive than avifauna overall. These results demonstrate the value of MODIS LST data for measuring ecologically-relevant heat waves across large regions. Ecologically, these findings highlight the importance of extreme events for avian biodiversity and the considerable variation in response to environmental change associated with different functional groups and geographic regions. The magnitude of the relationships between avian abundance and heat waves reported here raises concerns about the impacts of more frequent and severe heat waves in a warming climate.
\end{abstract}

(c) 2010 Elsevier Inc. All rights reserved.

\section{Introduction}

The loss of biodiversity is the least reversible form of global change, and has been observed recently in numerous taxonomic groups, including birds (Novacek \& Cleland, 2001). Biodiversity decline results from numerous interacting factors, including habitat loss and fragmentation (Fahrig, 2003), invasive species (Courchamp et al., 2003), overexploitation (Hutchings, 2000), and climate change

\footnotetext{
* Corresponding author. Department of Geography, University of Nevada, Reno, MS0154 Reno, NV 89558, USA. Tel.: + 1775784 5573; fax: +1 7757841058.

E-mail addresses: talbright@unr.edu (T.P. Albright), apidgeon@wisc.edu (A.M. Pidgeon), cdrittenhous@wisc.edu (C.D. Rittenhouse), clayton@stat.wisc.edu (M.K. Clayton), cflather@fs.fed.us (C.H. Flather), pdculbert@wisc.edu (P.D. Culbert), radeloff@wisc.edu (V.C. Radeloff).
}

(Parmesan \& Yohe, 2003). A factor attracting increased attention, climate change encompasses changes in mean temperature and precipitation throughout the year and changes in variability among years. In some regions of North America, changes in interannual variability may be the most evident manifestation of climate change (Diffenbaugh et al., 2008) and more frequent extreme events such as heat waves are predicted (IPCC, 2007; Meehl \& Tebaldi, 2004). Heat waves, which typically connote two or more consecutive days of hot and higher than average temperatures for a particular time period, have been linked to increased mortality among some wildlife species (Gordon et al., 1988; Jiguet et al., 2006).

However, relatively little is known about their effects among avian communities across diverse regions. Communities represent groups of species interacting at particular locations and may be subdivided according to taxonomic and functional characteristics. Responses by avian communities to heat waves are of particular interest for several 
reasons. Birds are near-ubiquitous, mobile, and responsive at fine temporal scales. Birds are of conservation interest because of a number of population declines in the United States (North American Bird Conservation Initiative - U.S. Committee, 2009) and worldwide, where one in eight species is threatened (BirdLife International, 2008). Birds also perform a broad array of ecosystem services including pollination, pest control, and recreation (Sekercioglu, 2006). In our study region, threats to already-diminished grassland habitats and associated grassland-specialist birds are of particular concern (Herkert, 1995). Finally, birds, being generally conspicuous, are among the most well monitored taxonomic groups.

Effectively relating heat waves to avian response requires spatially- and temporally-detailed data. Remote sensing plays an important role in informing biodiversity science (Turner et al., 2003), and Moderate Resolution Imaging Spectroradiometer (MODIS) data offer retrievals of biophysical parameters such as land surface temperature (LST, Wan et al., 2003) with an attractive balance of spatial and temporal resolution. Remote measurements of LST have been widely used in energy balance and agro-meteorology studies (e.g. Anderson et al., 2007; Dakhore et al., 2008), but much less in ecological and biogeographic studies (but see Mildrexler et al., 2007). Concurrently, advances in databases and interpolation algorithms have spurred the availability of gridded weather and climate summaries based on networks of ground measurements (e.g. Daly et al., 2002; Hijmans et al., 2005). The relative strengths of satellite and ground measurements for biodiversity and ecological studies are not clear. There are several key differences between these remotelysensed and ground-based data sources. Meteorological stations measure air temperature, $\mathrm{T}_{\mathrm{air}}$, typically at $1.5-2.0 \mathrm{~m}$ in height. In contrast, remote sensors measure land surface temperature, which, though correlated, can differ greatly from $\mathrm{T}_{\mathrm{air}}$. Land surface temperature is heavily influenced by latent heat flux associated with evapotranspiration and is thus related to vegetation condition (Zaitchik et al., 2006). Because birds are often dependent on vegetation, this property of LST may render it an especially useful indicator of individual-scale weather conditions. For both $\mathrm{T}_{\text {air }}$ and LST, it is important to consider whether there are critical periods in the year when birds are more sensitive to extremes or whether entire seasons of above normal temperatures are most relevant. Lagged demographic responses (e.g. reduced recruitment) may influence whether population and community effects are more apparent during the year of a heat wave or in subsequent years.

Heat waves can elicit direct and indirect responses from birds and other animal taxa. Direct responses may include changes in behavior (Guthery et al., 2005), reduced recruitment (Guthery et al., 2001), or death (Finlayson, 1932). The same responses may occur indirectly, through effects of heat on resources (e.g. cover, forage, prey) that animals use (Becker et al., 1997). Responses to severe weather can also include dispersal to less-affected areas (Mooij et al., 2002). Responses are likely to depend on functional traits of species and groups of species For instance, because air temperatures can differ drastically from surface temperatures, the vertical stratum (i.e. ground- vs. canopy-level) that birds occupy likely influences their sensitivity to heat waves. Migratory habit can affect both the amount of time spent in a locale and the way habitat is selected. Geographic location may also influence the severity of heat waves as well as the degree to which animals are adapted to thermal stressors (Yarbrough, 1971).

Our goal was to identify relationships between heat waves and changes in the structure of avian communities. Our primary hypothesis was that both abundance and species richness decline due to heat waves, but that abundance would be more affected because the abundance of individual species has to decline to zero before producing a decline in species richness. We asked two sets of supporting questions. The first set aimed to identify the most relevant types of heat waves and indicators for avifauna. Specifically, we asked whether avian communities 1a) are more related to remotely-sensed measurements of LST or $\mathrm{T}_{\text {air }}$ from interpolated ground measurements, with the expectation that they would be more related to LST than to $\mathrm{T}_{\text {air }}$ because of the influence of vegetation condition on the former; $1 \mathrm{~b}$ ) are more related to temperature anomalies (departures from means) or exceedances (above normal temperatures only), anticipating that that exceedances, by quantifying only above normal temperatures, would be better indicators; and 1c) respond differently to heat waves occurring during different same-season and previous-season time periods, hypothesizing that avian communities would respond more strongly to previous-season heat waves because of nest failure and that dispersal would be more common responses than outright adult mortality.

The second set of questions focused on identifying how avian response to heat waves varied with functional trait and geographic region. Specifically, we asked $2 \mathrm{a}$ ) whether nest stratum and $2 \mathrm{~b}$ ) migratory habit influence avian response to heat waves with the expectation that birds nesting in the more thermally stressful ground level would respond most negatively and that responses would diminish with migratory distance as migration-related mortality would dominate the demography of migratory birds; and 2c) how responses vary among four ecoregions with different climatic regime, hypothesizing that responses would be greatest in warmer ecoregions where thermal stress would be greater.

\section{Methods}

\subsection{Study region}

Our study area is a large and diverse region, encompassing 15 states of the central United States (3.7 million $\mathrm{km}^{2}$; Fig. 1), and including both eastern and western US bird species. Largely temperate, the region is centered on the Great Plains, a gently sloping prairie landscape dominated by agriculture and rangelands. In the West are the Rocky Mountains and in the East are the Southern Mixed Forest, Ozark Highlands, and Eastern Broadleaf Forest. Excluding mountainous areas, there is a gradient of declining precipitation from east $\left(80-140 \mathrm{~cm} \mathrm{yr}^{-1}\right)$ to west $\left(25-35 \mathrm{~cm} \mathrm{yr}^{-1}\right)$. The mountainous west experiences more precipitation (e.g. $95 \mathrm{~cm} \mathrm{yr}^{-1}$ ), much of it in the form of snow. Mean maximum temperature in July generally exceeds $35^{\circ} \mathrm{C}$ in the south, but declines to less than $25^{\circ} \mathrm{C}$ in the north and often less than $15^{\circ} \mathrm{C}$ in alpine areas.

\subsection{Avian data}

We obtained 2000-2007 data from the North American Breeding Bird Survey (BBS; (USGS, 2008). Our study area includes 1233 BBS routes, each $39.4 \mathrm{~km}$ in length. Along each route, 50 3-minute point counts are conducted near-dawn annually during peak breeding season (most often during June) in which all birds seen or heard within $400 \mathrm{~m}$ are recorded. We removed data from first-year observers and those having inclement weather at the time of the survey (Link \& Sauer, 1997; Sauer et al., 2004). For each suitable year within each route ("route-year"), we summed counts of individual birds for a) North American landbirds ("ALL"; (Rich et al., 2004), b) three different migratory groups ("RESIDENT", "SHORTDIST", and "NEOTROP"; (Rappole, 1995), and c) two guilds related to nest location ("GROUND" and "CANOPY"; (Pidgeon et al., 2007), for a total of 6 avian groups; (Table 1, complete membership lists in Table S1). We excluded rare species ( $<30$ route-year occurrences over the history of BBS in the conterminous US) and marine or aquatic species, which are poorly sampled by BBS (Bystrak, 1981). In addition to abundance, we tabulated richness, i.e. the number of species identified in each group. 


\subsection{MODIS land surface temperature}

From the MODIS sensor flown aboard the National Aeronautics and Space Administration's (NASA) Terra satellite, we obtained data from 2000 to 2008 MOD11C2 and MOD11C3 LST products composited for eight-day and one-month periods, respectively. MODIS LST data are based on the generalized split-window algorithm (Wan \& Dozier, 1996) and day/night algorithm (Wan \& Li, 1997) that resolve ambiguities arising from variable emissivity and are accurate to within $1{ }^{\circ} \mathrm{C}$ in most cases (Wan, 2008; Wan \& Li, 2008; Wan et al., 2003). The summer seasonal windows from day-of-year 153 to 265 (June to midSeptember) for MOD11C2 and June, July, and August for MOD11C3 were chosen based on examination of correlation coefficients and to capture leaf-on conditions for most vegetation types in the region. We excluded data with poor calibration, cloud contamination, or other quality issues based on the LST product quality assurance flags provided. For each pixel and time period, we subtracted 2000-2008 mean values to obtain temperature anomalies for each year. Images were projected into Albers equal-area projection with $5 \mathrm{~km} \times 5 \mathrm{~km}$ cells, which is approximately equivalent to the $0.05^{\circ}$ by $0.05^{\circ}$ resolution of the MODIS products. The MODIS instrument aboard Terra collects images in the late morning, local time. While MODIS data from the Aqua platform, with its early afternoon overpass, would have provided measurements of LST closer to daily temperature maxima, those data were only available following 2002 and suffered from a large number of unacceptable quality flags over our study region.

In order to relate LST to BBS routes, we calculated mean LST within a $20-\mathrm{km}$ buffer around BBS route centroids. In addition to encompassing the entire length of the route, this distance is comparable to the median maximum natal dispersal distance $(31 \mathrm{~km})$ of 76 avian species for which it has been observed (Sutherland et al., 2000), indicating that the buffer captures a biologically relevant area. To evaluate the influence of LST on avifuana in year t, we considered monthly anomalies for each summer month (June, July, and August) of the previous year $(t-1)$ as well as for June of the same year $(t)$ as the BBS data (Table 2). We excluded July and August from year $t$ analysis because it would involve temperature data collected after the BBS observations were made in a given year. While many other metrics could have been considered, we selected these as a balance between diverse formulations, use of readily-available data products, and a manageable number of metrics to analyze.

\subsection{Air temperature}

Monthly maximum air temperature ( $\mathrm{T}_{\text {air }}$ ) data (means of daily maxima for each month) for 2000-2005 (the last available year) were obtained from the 1-km resolution PRISM dataset (PRISM Climate Group, 2009) for the summer months. We calculated mean $T_{\text {air }}$ for each summer month, subtracted these from monthly $\mathrm{T}_{\text {air }}$ values for each year, and resampled to $5-\mathrm{km}$ cells to obtain monthly $\mathrm{T}_{\text {air }}$ anomalies. As with LST, we considered year $t-1$ for each summer month as well as year $t$ for June, the other months occurring after routes are surveyed (Table 2). We then intersected BBS route centroids with this grid to calculate monthly anomalies for each BBS route.

\subsection{Seasonal summaries}

From each year of the LST and $\mathrm{T}_{\text {air }}$ datasets, we calculated the average monthly anomaly and average exceedances over the summer (Table 2). We defined exceedances, $T_{E}$, as the deviation above the 2000-2008 mean temperature, $\bar{T}$, for a given period (8 days for MOD11C2 and 1 month for MOD11C3 and PRISM), such that:

$T_{E}=T-\bar{T}$ for $T>\bar{T}$ and $T_{E}=0$ for $T \leq \bar{T}$
Our rationale for using exceedances was that a cumulative index of high temperatures ignoring temperature variations below the mean would be a better proxy for heat wave conditions. A total of 14 monthly and seasonal heat wave metrics were considered, including same year $(\mathrm{t})$ and previous year $(\mathrm{t}-1)$ metrics (Table 2 ).

\subsection{Analysis}

To explore the relationship between LST and $\mathrm{T}_{\text {air }}$, we calculated a series of linear regression models. To characterize the relationship between heat wave metrics and avian abundance and richness, we developed a series of linear mixed effect models using the nlme package within the $\mathrm{R}$ language and environment for statistical analysis (Pinheiro et al., 2007; R Development Core Team, 2010). We used abundance (transformed as $\ln$ (abundance +1 ) to normalize the distributions) and species richness (untransformed) as response variables. We included a fixed-effect for ecoregion to account for broad-scale variation in abundance and richness among four broad regions with differing climatic regimes (modified from Bailey, 1995): the Humid North occupying the northeastern portion of the study region, the Dry North in the north central, the Montane West, which is intermediate in precipitation, with most falling as snow, and the South, which experiences the highest temperatures (Fig. 1b). We included a heat wave metric by ecoregion interaction term, which allowed fixed effects of temperature variation to be estimated for each ecoregion. While our objective was not to understand finer-scale spatial variations in abundance and richness among the routes, it was nonetheless an important source of variability in our dataset. Thus, we included a random effect for BBS route. Similarly, different BBS observers possess different skill levels in detecting birds, which may result in biased estimates of abundance and richness (Sauer et al., 1994), prompting us to treat observers as random effects nested within BBS routes. Finally, we added a continuous time autoregressive component to account for temporal autocorrelation. The resulting model for predicting the richness or $\ln ($ abundance +1$)$ was:

$y=\beta_{0 i}+\beta_{1 i} X_{j k}+b_{j}+b_{k}+e(t)$

where the $\beta_{0 i}$ and $\beta_{1 i}$ are the intercept and slope for the specified heat wave metric at ecoregion $i, X_{\mathrm{jk}}$ is the value of a heat wave metric at route $j$ observed by observer $k, b_{j}$ and $b_{k}$ are random effects for route $j$ and observer $k$, and $e(t)$ is a continuous time autoregressive process of order 1 , which accommodates irregularly spaced samples in time. All models were fit using restricted maximum likelihood estimation.

We compared models using the LST and $\mathrm{T}_{\text {air }}$ metrics for each of the groups. In this step, we used a subset of the 2000-2005 dataset having complete observations in a year for each metric $(n=3796$, an average of 3.6 years of observation along 1048 routes) so that sample size was constant. Comparisons were based on the Akaike Information Criterion (AIC, Akaike, 1974), which is a likelihood-based indicator of relative fit, penalized for model complexity. Values of AIC for various models based on the same dataset may be directly compared and ranked using $\Delta_{\mathrm{i}}$, the difference in AIC between the best model and a particular model in question. As a rule of thumb, $\Delta_{\mathrm{i}}<2.0$ indicates a similar level of support as the "best" model (Burnham \& Anderson, 2002). Because of the short time series of PRISM-based $T_{\text {air }}$ estimates, we generated a second set of model comparisons based exclusively on complete MOD11C2 and MOD11C3 datasets, which additionally allowed inclusion of 2006-2007 data $(n=5297$, an average of 5.1 years of observation). We then refit the most supported abundance and richness models for each group using all data available for each heat wave metric (up to $n=6060$ ) to obtain coefficient estimates. We examined variograms and corresponding confidence envelopes of residuals from the best models in search of residual spatial autocorrelation but found none. 
a

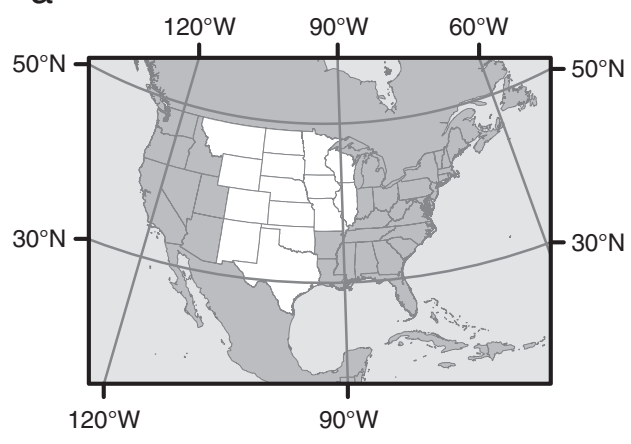

b

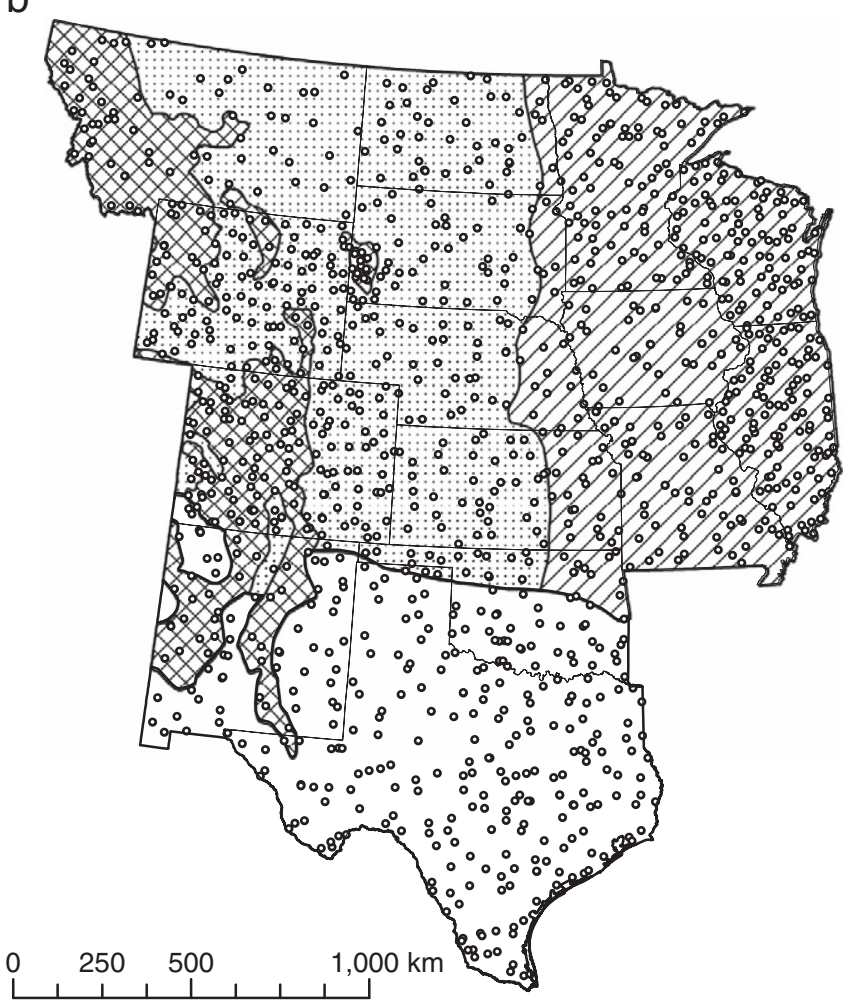

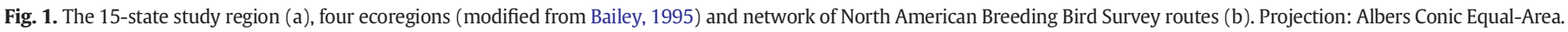

Because of the log-scaling of response variables and differences in mean abundance and richness among ecoregions and assemblages in this study, estimated model coefficients did not provide a practical gauge of the apparent effects of heat waves on avian communities. In order to better understand these, we quantified in percentage the magnitude of avian community changes associated with a series of scenarios based on fitted models. We focused on scenarios representing severe heat waves occurring with an approximate 50 -year return interval (98th percentile) based on the record of climate conditions contained in our datasets. First, we considered a prolonged heat wave in which previous year $(\mathrm{t}-1)$ 8-day LST exceedances during summer $($ M2LSTex -1$)$ averaged $3{ }^{\circ} \mathrm{C}$ above normal. We also considered two acute within-month heat waves in which mean LST for August of year $\mathrm{t}-1\left(\right.$ M3LST08 $\left._{\mathrm{t}-1}\right)$ and June of year $\mathrm{t}\left(\mathrm{M}_{\mathrm{LSTO}} \mathrm{f}_{\mathrm{t}}\right)$ were $5{ }^{\circ} \mathrm{C}$ above normal temperatures for each BBS route. In quantifying changes, we multiplied model coefficients by the metric values identified as the 50 -year events to predict the percent change in abundance and richness of average routes in each ecoregion under a neutral (neither positively nor negatively biased) observer.

\section{Results}

We found highly significant regression slopes $(P<0.0001$ in all cases) between MODIS LST and PRISM-based $\mathrm{T}_{\text {air }}$ measurements used in this study (Fig. 2). The strength of correlation between these temperature measurements varied considerably among regions and among time periods, with stronger correlations occurring later in the summer. Total bird abundance on routes ranged from 83 to 4764 individuals and richness varied from 8 to 85 species. Abundance and richness were correlated over time within routes, with a median Spearman rank correlation of 0.43 (Wilcoxon signed-rank test, $P<0.0001$ ). Richness and abundance were highest in the northeastern and lowest in the southwestern portions of the study area. SHORTDIST were the most abundant group (median $=293$ individuals per route) and RESIDENT were the least (median=39). Richness was highest among NEOTROP (median $=22$ species per route) and lowest among RESIDENT (median $=6$ ). While mostly within $1.5^{\circ} \mathrm{C}$, monthly temperature anomalies exceeded $+6{ }^{\circ} \mathrm{C}$ in approximately $1 \%$ of cases, but were never greater than $+10{ }^{\circ} \mathrm{C}$.

Table 1

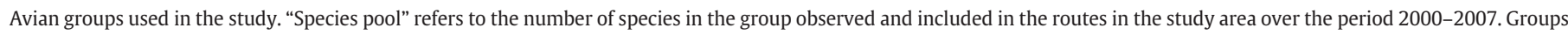
within themes are mutually exclusive but not exhaustive, as some birds not assigned a group may nest across strata or have multiple or unknown migratory habits.

\begin{tabular}{|c|c|c|c|c|}
\hline Group theme & Group & Short name & Species pool & Description \\
\hline Avifauna & All & ALL & 327 & North American landbirds \\
\hline \multirow[t]{2}{*}{ Nest location } & Ground-nesting & GROUND & 98 & Nest within $1 \mathrm{~m}$ of ground \\
\hline & Midstory-/canopy-nesting & CANOPY & 117 & Nest more than $1 \mathrm{~m}$ above ground \\
\hline \multirow[t]{3}{*}{ Migratory habit } & Permanent residents & RESIDENT & 79 & Do not migrate away from breeding range \\
\hline & Short distance migrants & SHORTDIST & 84 & Winter north of Tropic of Cancer \\
\hline & Neotropical migrants & NEOTROP & 158 & Winter south of Tropic of Cancer \\
\hline
\end{tabular}


Table 2

Heat wave metrics used.

\begin{tabular}{|c|c|c|c|c|}
\hline Variable & Measurement & Source & Temporal grain & Time period \\
\hline $\mathrm{T}_{\mathrm{air}} 06_{\mathrm{t}}$ & June mean $\mathrm{T}_{\text {air }}$ anomaly & PRISM & Month & June \\
\hline M3LST06 $t_{t}$ & June LST anomaly & MOD11C3 & Month & June \\
\hline $\mathrm{T}_{\mathrm{aia}} 06_{\mathrm{t}-1}$ & Lagged June mean $\mathrm{T}_{\text {air }}$ anomaly & PRISM & Month & June $_{t-1}$ \\
\hline M3LST06 ${ }_{t-1}$ & Lagged June LST anomaly & MOD11C3 & Month & June $_{t-1}$ \\
\hline $\mathrm{T}_{\mathrm{air}} 07_{\mathrm{t}-1}$ & Lagged July mean $\mathrm{T}_{\text {air }}$ anomaly & PRISM & Month & July $_{\mathrm{t}-1}$ \\
\hline $\mathrm{M} \mathrm{LSTO7}_{\mathrm{t}-1}$ & Lagged July LST anomaly & MOD11C3 & Month & July $_{t-1}$ \\
\hline $\mathrm{T}_{\mathrm{air}} 08_{\mathrm{t}-1}$ & Lagged August mean $\mathrm{T}_{\text {air }}$ anomaly & PRISM & Month & $\operatorname{Aug}_{\mathrm{t}-1}$ \\
\hline M3LST08 $_{t-1}$ & Lagged August LST anomaly & MOD11C3 & Month & $\operatorname{Aug}_{t-1}$ \\
\hline $\mathrm{T}_{\text {air }}$ mean $_{\mathrm{t}-1}$ & Summer average max. $\mathrm{T}_{\text {air }}$ & PRISM & Month/3-month & $J J A_{t-1}^{a}$ \\
\hline M3LSTmean $_{t-1}$ & Summer average land surface temperature & MOD11C3 & Month/3-month & $J J A_{t-1}$ \\
\hline M2LSTmean $_{\mathrm{t}-1}$ & Summer average land surface temperature & MOD11C2 & 8-day/112-day & $\mathrm{d} 153-\mathrm{d} 264_{\mathrm{t}-1}$ (1 Jun-20 Sep) \\
\hline $\mathrm{T}_{\text {air }} \mathrm{ex}_{\mathrm{t}-1}$ & Mean summer maximum $\mathrm{T}_{\text {air }}$ exceedance & PRISM & Month/3-month & $J J A_{t-1}$ \\
\hline M3LSTex $_{t-1}$ & Mean summer land surface temperature exceedance & MOD11C3 & Month/3-month & $J J A_{t-1}$ \\
\hline M2LSTex $_{t-1}$ & Mean summer land surface temperature exceedance & MOD11C2 & 8-day/112-day & $\mathrm{d} 153-\mathrm{d} 264_{\mathrm{t}-1}$ (1 Jun-20 Sep) \\
\hline
\end{tabular}

a June, July, August.

Comparison of the models based on the complete-observations dataset (2000-2005 heat wave metrics) revealed that models of abundance and richness based on monthly or season-long metrics from MODIS LST were clearly superior to their corresponding PRISMbased $\mathrm{T}_{\text {air }}$ alternatives. In all cases, AIC differences between the best MODIS- and PRISM-based models were greater than 25, indicating that PRISM-based metrics had considerably lower explanatory power (Table S2). Thus, subsequent results presented are based on 20002007 MOD11C2 and MOD11C3 datasets. In this MODIS-only comparison set, models also varied widely in support, as gauged by $\Delta_{\mathrm{i}}$ (Table 3). August MOD11C3 LST anomalies from the previous year (M3LST08 $\mathrm{t}_{-1}$ ) resulted in the most supported models of abundance of ALL, GROUND, and SHORTDIST birds. Season-long 8-day LST exceedance from the previous year $\left(M_{2} L_{S T e X}-1\right)$ was the best predictor of the abundance of CANOPY and RESIDENT birds. Sameyear June MOD11C3 LST anomalies (M3LST06 ${ }_{t}$ ) formed the basis of the most supported model for NEOTROP abundance. Models based on July measurements were generally less supported than those based on other months. In each group, the best abundance model was clearly better than all competing models, indicated by $\Delta_{\mathrm{i}}>4.0$. Season-long exceedances using 8-day MOD11C2 (M2LSTex -1$)$ were consistently better than models based on mean anomalies.

Comparisons of support among richness models also indicated the utility of 8-day LST exceedance from the previous year (M2LSTex -1$)$, which was the best predictor of richness for all groups except GROUND (Table 3). For this group, using monthly exceedances $\left(\right.$ M3LSTex $\left._{t-1}\right)$ resulted in the best model.

Avian abundance and richness usually, but not always, declined during or after heat waves (Table 4, complete information in Table S3). This was particularly true in the South ecoregion, where nine of twelve models indicated significant negative avian responses to increased temperatures. However, in the Humid North ecoregion, the abundance and richness of RESIDENT (significantly) and most other groups (non-significantly) increased with elevated temperatures.

Fig. 3 depicts the impacts of the three heat wave scenarios on avian communities in our study region. A season-long heat wave with mean M2LSTex $\mathrm{t}_{-1}$ of $+3{ }^{\circ} \mathrm{C}$, resulted in particularly large changes in abundance and richness. Most groups saw declines in both abundance and richness in the Montane and South ecoregions, with the largest declines in RESIDENT bird abundance, which declined $19.4 \%$ and $12.8 \%$, respectively. In contrast, RESIDENT birds in the Humid North and NEOTROP birds in the Dry North increased by $15.0 \%$ and $11.6 \%$, respectively. Here, and in other scenarios unless otherwise noted, similar but more modest patterns of change occurred for avian richness. For instance, in the Montane ecoregion, RESIDENT richness declined by $6.3 \%$.

Under an acute heat wave with M3LST0 $8_{t-1} 5^{\circ} \mathrm{C}$ above normal, modeled changes were smaller, but mostly negative, with the largest declines in the South, where the abundance of ALL and GROUND declined by $8.3 \%$ and $11.6 \%$, respectively, by the following year. Declines in abundance also occurred among several avian groups in the Dry North and Montane regions. Declines in abundance and richness during years with M3LST06 $5^{\circ} \mathrm{C}$ above normal were generally more modest and, in some cases, increases occurred. In particular, NEOTROP and GROUND abundance declined by $9.8 \%$ and $7.8 \%$ in the Dry North, and RESIDENT abundance increased by $8.7 \%$ and $5.2 \%$ in models in the Humid and Dry North respectively.

\section{Discussion}

\subsection{Metrics and timing of heat waves}

As expected, anomalies of remotely-sensed land surface temperature and interpolated air temperature derived from meteorological station networks were correlated in all ecoregions and time periods examined. However, MODIS LST provided more ecologically-relevant information as models based on LST were clearly superior to those based on $\mathrm{T}_{\text {air }}$ (Table S2). From a practical standpoint, this is encouraging, as meteorological networks suffer from poor coverage in many parts of the world and deriving high quality interpolated surfaces is challenging, meaning that spatial and temporal data continuity is not assured. Furthermore, satellite measures of temperature at the land surface, as opposed to the air, may also be advantageous. Specifically, measurements of LST are related to vegetation conditions with, for example, sharp rises associated with disturbance events (Mildrexler et al., 2007). Because we use mean LST over larger areas, the effect of small-scale disturbances is moderated, but likely still contributes to LST values. At broader scales, drought can be associated with heat waves (Trenberth \& Shea, 2005) and likely entails elevated LST. Thus, MODIS LST may act as a synthetic indicator of both temperature and vegetation condition enhancing predictive utility over measurement of these aspects individually and producing a greater dynamic range than $\mathrm{T}_{\text {air }}$ (e.g. the interquartile ranges of temperature anomalies in July are $3.16^{\circ} \mathrm{C}$ and $2.48{ }^{\circ} \mathrm{C}$ for LST and $\mathrm{T}_{\text {air }}$, respectively; Fig. 2). Indeed, comparison with previous results examining the influence of drought on avian communities (Albright et al., 2010) reveals stronger associations with LST than with drought.

Both long-lasting as well as short but intense heat waves late in the breeding season influenced avian communities in our study. Avian community structure was most related to 1-year lagged metrics corresponding to either season-long or late-season heat waves. In most locations, temperature maxima in August are higher than in June, so heat waves are likely more intense during this time as well. On the other hand, responses of birds to July metrics were less strong despite the occurrence of the year's highest temperature maxima in this month at most locations. For many species, August corresponds to a time of high vulnerability for juvenile birds, as they have generally 

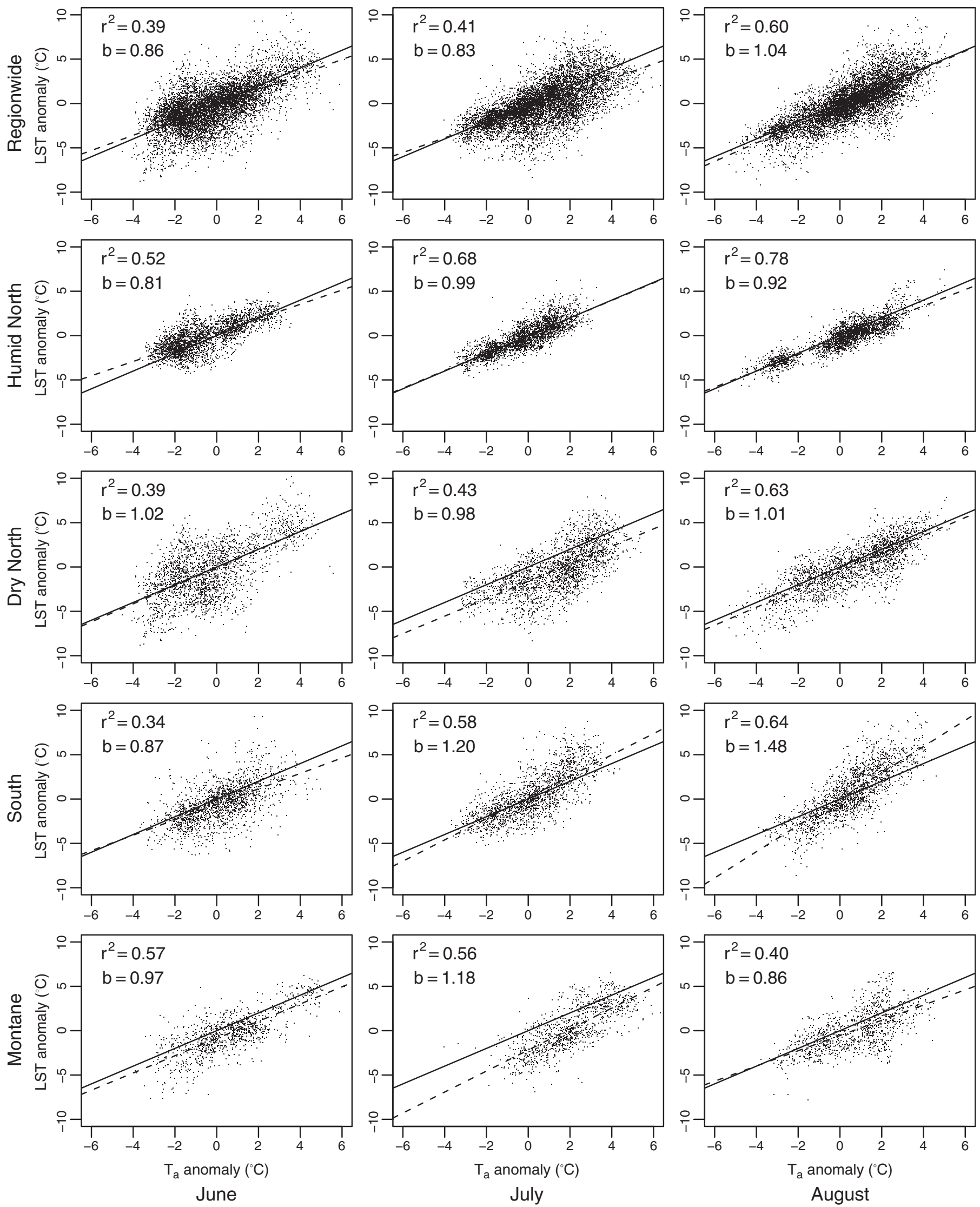

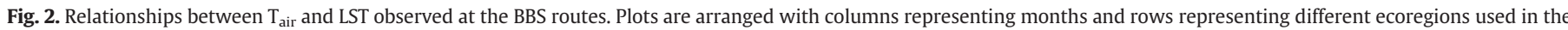
study. Coefficient of determination $\left(R^{2}\right)$, slope (b), a 1:1 line (solid line), and linear regression fit (dashed line) are shown for each plot. 


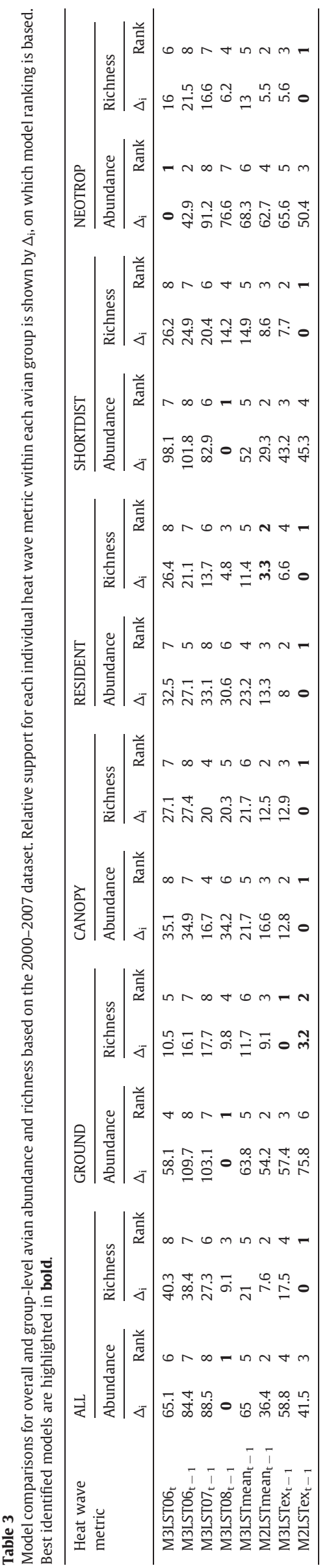

fledged and are largely independent of parental care (Anders et al., 1997). It is also possible that birds are more sensitive to end-of season conditions when confronting dispersal decisions than to conditions earlier in the season. For example, post-breeding song can be an important social cue for dispersing individuals, influencing habitat selection the following year (Betts et al., 2008). For season-long metrics, exceedances based on MOD11C2 8-day composites, rather than mean temperatures or measurements at monthly intervals, were more predictive of avian community changes. This suggests that 1 ) it is positive temperature anomalies specifically (e.g. associated with heat waves) that drive avian response and 2) finer temporal resolution (8-day vs. month) is beneficial for detecting ecologicallyrelevant heat waves.

\subsection{Relationships between heat wave metrics and avian community change}

Avifauna diversity is highly variable in time (Bengtsson et al., 1997; Rittenhouse et al., 2010). Our results suggest that a substantial portion of this variability can be explained by the occurrence of heat waves (Table S3). For a majority of avian groups and ecoregions, the most supported models indicated negative relationships between heat waves and avian abundance (Table 4), which is consistent with observations of avian populations following the 2003 European heat wave (Jiguet et al., 2006). A weaker, but similarly negative relationship between avian richness and heat wave metrics was observed for most ecoregions and avian groups. These relationships suggest that heat waves tend to reduce avian abundance, and to a lesser extent, richness, both during the same year and the subsequent year. Several mechanisms may underlie this relationship. Avian declines concurrent with heat waves may be caused by movements away from the breeding grounds and, in extreme cases, mortality (Finlayson, 1932). Because many of the heat waves observed during this study were mild, movement away from heat wave-affected areas, rather than mortality, appears a more likely cause. Reductions in abundance in the breeding season following a heat wave may additionally be due to reduced reproduction (Lusk et al., 2001), as individuals may choose to invest fewer resources in reproduction during heat wave conditions, or reduced young of the year survival. Furthermore, operating as informed dispersers (Clobert et al., 2009), individuals experiencing poor outcomes in one location may select different breeding ranges in following years, sometimes prospecting for locations occupied by successful conspecifics prior to migration to their wintering range (Doligez et al., 2004; Reed et al., 1999). It is also possible that during heat waves, birds may be present but be less likely to be detected. While the cooler temperatures associated with the near-dawn timing of the survey free birds from the need to seek shade (becoming harder to detect), it is possible that even early-morning vocalizations could be reduced if breeding has already been forgone. However, such detectability issues would only apply to same-year relationships and not to those observed during the year following a heat wave. Because of these reasons, we do not think that variable detectability influenced our findings.

Species richness was considerably less related to heat waves than abundance. Only in rare cases (e.g. GROUND and SHORTDIST in the Dry North following season-long heat waves, Fig. 3), was the response by richness significant when abundance was not. Certainly, at a species level, declines in abundance precede extirpation. Our results show that this relationship tends to hold at the community level, as individual species must first decline in abundance before extirpation from the community reduces species richness, suggesting a longer time scale for richness response than examined in this study.

\subsection{Functional and geographic variation in response}

Sensitivity to the timing and duration of heat waves varied among migratory groups (Tables 3 and 4). RESIDENT birds were most strongly 
Table 4

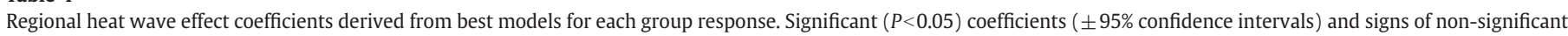

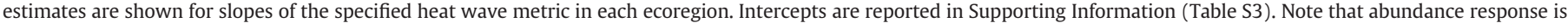
scaled as: $\ln ($ abundance +1 )

\begin{tabular}{|c|c|c|c|c|c|c|}
\hline Group & Response & Metric & Humid North & Dry North & Montane & South \\
\hline \multirow[t]{2}{*}{ ALL } & Abund & M3LST08 $_{t-1}$ & + & $-0.0098 \pm 0.0034$ & - & $-0.0173 \pm 0.0036$ \\
\hline & Rich & M2LSTex -1 & + & - & $-0.5905 \pm 0.2929$ & $-0.3434 \pm 0.1900$ \\
\hline \multirow[t]{2}{*}{ GROUND } & Abund & M3LST08 $_{t-1}$ & - & $-0.0126 \pm 0.0045$ & $-0.0087 \pm 0.0059$ & $-0.0244 \pm 0.0046$ \\
\hline & Rich & M3LSTex $_{t-1}$ & + & - & - & + \\
\hline \multirow[t]{2}{*}{ CANOPY } & Abund & M2LSTex $_{t-1}$ & + & + & $-0.0242 \pm 0.0204$ & $-0.0325 \pm 0.0132$ \\
\hline & Rich & M2LSTex $_{t-1}$ & - & + & $-0.3271 \pm 0.1750$ & $-0.1407 \pm 0.1121$ \\
\hline \multirow[t]{2}{*}{ RESIDENT } & Abund & M2LSTex $_{t-1}$ & $+0.0452 \pm 0.0293$ & + & $-0.0697 \pm 0.0359$ & $-0.0455 \pm 0.0230$ \\
\hline & Rich & M2LSTex $_{t-1}$ & $+0.1229 \pm 0.0904$ & + & $-0.1324 \pm 0.1108$ & $-0.0816 \pm 0.0693$ \\
\hline \multirow[t]{2}{*}{ SHORTDIST } & Abund & M3LST08 $_{t-1}$ & - & $-0.0115 \pm 0.0042$ & $-0.0124 \pm 0.0056$ & $-0.0191 \pm 0.0044$ \\
\hline & Rich & M2LSTex -1 & + & $-0.1098 \pm 0.0949$ & $-0.2183 \pm 0.1424$ & $-0.1412 \pm 0.0882$ \\
\hline \multirow[t]{2}{*}{ NEOTROP } & Abund & M3LST06 $_{t}$ & + & $-0.0206 \pm 0.0038$ & - & - \\
\hline & Rich & M2LSTex $_{t-1}$ & - & - & $-0.2926 \pm 0.1992$ & - \\
\hline
\end{tabular}

related to season-long heat waves, based on the magnitude of their response irrespective of sign. The availability of resources over the breeding season may influence the ability of RESIDENT birds to produce optimum fat reserves, which in turn influences winter survival (Rogers \& Smith, 1993). In contrast, NEOTROP birds were most influenced by elevated June temperatures (in the Dry North), which in some cases corresponds to the timing of their arrival in their breeding range. Relative to other migratory groups NEOTROP birds are less-affected by previous-year conditions, particularly during August. For some members of this group (e.g. the Common Nighthawk, Chordeiles minor, Western Tanager (Piranga ludoviciana) Black-headed Grosbeak (Pheucticus melanocephalus), Northern Waterthrush (Seiurus noveboracensis), Black-and-white Warbler (Miniotilta varia)) migration is already underway before in August. While not widespread among the species in this study (Carlisle et al., 2005; Murray, 1966), such early fall migration would tend to obscure any relationships between late summer heat waves and avian abundance and richness. Furthermore, the long migrations undertaken by Neotropical migrants increase their mortality risk, minimizing the relative contribution of the breeding season to total annual mortality. For instance, mortality rates of a population of Black-throated Blue Warblers (Dendroica caerulescens) during migration are approximately 15 times those experienced during stationary periods, constituting $85 \%$ of annual mortality (Sillett \& Holmes, 2002). However, mortality during and even following migration may be elevated following heat waves if body condition has been impaired because of lower food resources (Merila \& Svensson, 1997). Finally, we note as a caveat that some BBS routes in the South may be surveyed before June, obviously limiting the value of June temperature metrics in this region.

The sign of the relationship between avian community measures and heat wave metrics was strongly dependent on avian functional traits. We expected that the GROUND group would be most negatively affected by heat waves, and our results generally supported this. In response to the acute heat wave scenarios, GROUND abundance declined in all but the Humid North ecoregion, whereas for CANOPY abundance, declines were only predicted in the South during an acute August heat wave (Fig. 3). However, both GROUND and CANOPY abundance declined similarly following a season-long heat wave. Considerable variation associated with heat waves was observed for birds with different migratory habits. SHORTDIST birds were the most likely to decline in association with heat waves. Several factors may explain this. Among them, SHORTDIST birds stay in their breeding range for a longer duration than NEOTROP birds and because they do not travel as far as NEOTROP birds, they may have more time to scout suitable habitat at the beginning of the breeding season. Compared to RESIDENT birds, post-natal dispersal of SHORTDIST birds is greater (Paradis et al., 1998), which may grant them more flexibility in their selection of habitat to avoid areas impacted by heat waves during the previous year. In some cases, RESIDENT birds increased in association with heatwaves, even when other migratory guilds showed declines. We speculate that this may be a consequence of these species being adapted to highly variable conditions and possibly even exploiting reduced abundance of migrants during heat waves.

Our models indicated substantial ecoregional variation in the strength, and even sign, of avifauna-temperature relationships (Table 4, Fig. 3). In most cases, associations of heat waves were strongest in the South, where decreases in abundance and richness were most consistently negative and of the largest magnitude. Birds have a variety of adaptations to cope with extreme heat, but these have limits, particularly for small passerines (McNab, 1970; Weathers, 1997). In the South, birds may approach these limits and suffer thermal stress (McKechnie \& Wolf, 2010). The effect of season-long heat waves on montane avian communities was surprisingly large and warrants further study. Less strong, but also generally negative was the relationship between temperature and avian response in the Dry North. In the Humid North, however, abundance and richness of avifauna were generally positively related (significantly for RESIDENT) to heat waves. It may be that even considerably above normal temperatures, such as the $+5{ }^{\circ} \mathrm{C}$ anomalies we use in our June heat wave scenario, are not sufficient to exert substantial thermal stress on birds and the resources they use in this region. In fact, elevated temperatures associated with heat waves may increase vegetative and arthropod production where it is limited by temperature.

\subsection{Implications and conclusions}

We have developed and demonstrated the utility of a simple index of MODIS LST exceedance that could be modified to suit a variety of applications. While our study used a temperature threshold based on mean LST for each time period, other values based on relevant biophysical thresholds could be chosen, for example from physiological studies of thermal ecology. We have shown that heat waves may have strong and geographically- and functionally-dependent effects on avian communities in temperate North America. This supports the importance of considering the effect of extremes in studies of historic, contemporary, and future climate change (Parmesan et al., 2000). Yet, we consider our study to be conservative in a number of regards. Responses may be considerably more dramatic among individual species, at specific locations, and over longer time periods than our examination revealed over a broad spatial scale, for broad species groups, and over a short time period. For example, we included both common and uncommon species in our guilds and there is some evidence that less common species may be more responsive to extreme weather events (Albright et al., 2010).

It is also important to consider avian community response to heat waves in light of predictions of higher frequency and severity of heat waves due to climate change. The 2003 European heat wave was an extreme event with 8-day LST anomalies of about $15^{\circ} \mathrm{C}$ in some areas 
a

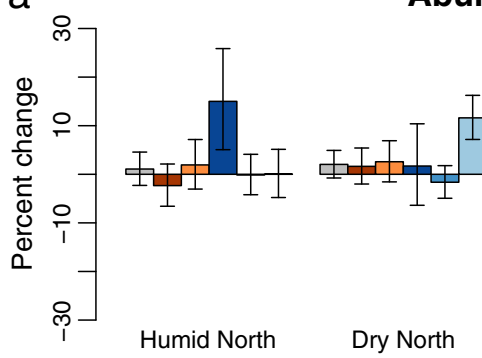

b

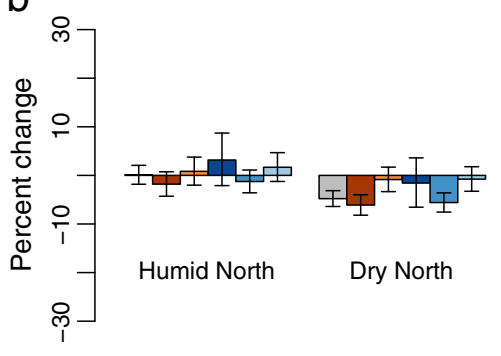

C

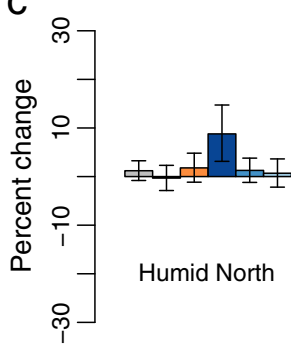

$\square$ ALL
Abundance

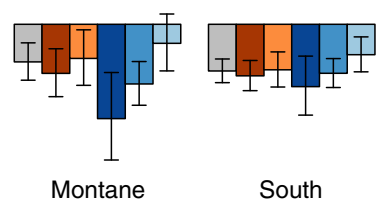

Species richness
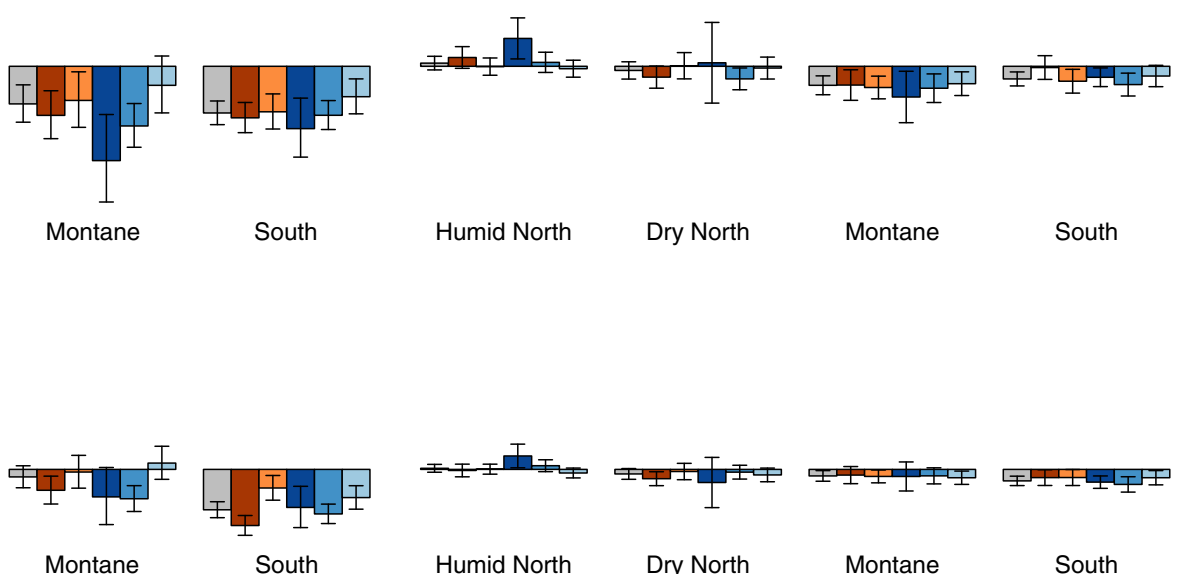

Montane

South

Dry North

Montane

South

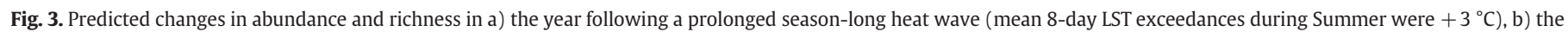

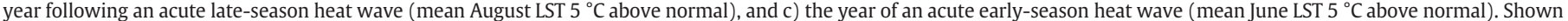

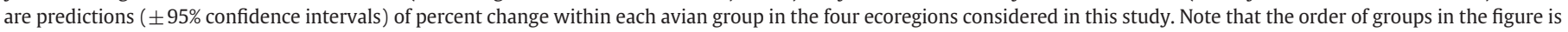
maintained to facilitate identification and comparison.

(Zaitchik et al., 2006). A comparable event occurring in North America could presage even larger declines in abundance and richness than predicted in our much more modest (50-year) heat wave scenarios, particularly if response is not linear at such extremes, as it appears in cases of human mortality (Filleul et al., 2006). Should such a dramatic heat wave occur, conservation managers may wish to consider targeted interventions, such as irrigation of critical habitat for the most threatened species. Heat waves may interact with other forms of environmental change to affect avifauna. In particular, a reduction in shrub cover stemming from the invasion of exotic grass and overgrazing may reduce the availability of fine-scale microclimatic refugia (D'Antonio \& Vitousek, 1992). Maintenance of these aspects of bird habitat may be important tools of land management. Finally, considerable uncertainty remains regarding the specific mechanisms by which heat waves reduce avian abundance and richness and longterm effects of increased heat wave occurrence, which we hope will be addressed in future studies.

Supplementary materials related to this article can be found online at doi:10.1016/j.rse.2010.08.024.

\section{Acknowledgements}

We gratefully acknowledge support for this research by the NASA Biodiversity Program and the NASA Interdisciplinary Science Program.
We thank the R project and the developers of the nlme, GeoR, and gplots modules. MODIS data were reprojected with the MODIS reprojection tool 4.0 (USGS EROS, Sioux Falls, SD, USA). All spatial summaries were calculated using ERDAS 9.0 (ERDAS, Inc., Atlanta, GA, USA) and ArcGIS 9.2 with the aid of Python 2.4 (ESRI, Redlands, CA, USA). M. Ozdogan, S. Stewart, and four anonymous reviewers provided helpful comments. Finally, we thank the many coordinators and volunteers who make BBS possible.

\section{References}

Akaike, H. (1974). New look at statistical-model identification. IEEE Transactions on Automatic Control, AC19, 716-723.

Albright, T. P., Pidgeon, A. M., Rittenhouse, C. D., Clayton, M. K., Flather, C. H., Culbert, P. D., et al. (2010). Effects of drought on avian community structure. Global Change Biology, 16, 2158-2170.

Anders, A. D., Dearborn, D. C., Faaborg, J., \& Thompson, F. R. (1997). Juvenile survival in a population of neotropical migrant birds. Conservation Biology, 11, 698-707.

Anderson, M. C., Norman, J. M., Mecikalski, J. R., Otkin, J. A., \& Kustas, W. P. (2007). A climatological study of evapotranspiration and moisture stress across the continental United States based on thermal remote sensing: 2. Surface moisture climatology. Journal of Geophysical Research-Atmospheres, 112.

Bailey, R. G. (1995). Description of the ecoregions of the United States. Washington, DC: USDA Forest Service.

Becker, P. H., Troschke, T. Behnke, A., \& Wagener, M. (1997). Starvation of Common Tern Sterna hirundo fledglings during heat waves. Journal Fur Ornithologie, 138, $171-182$.

Bengtsson, J., Baillie, S. R., \& Lawton, J. (1997). Community variability increases with time. Oikos, 78, 249-256. 
Betts, M. G., Hadley, A. S., Rodenhouse, N., \& Nocera, J. J. (2008). Social information trumps vegetation structure in breeding-site selection by a migrant songbird. Proceedings of the Royal Society B-Biological Sciences, 275, 2257-2263.

BirdLife International (2008). State of the world's birds: Indicators for our changing world. Cambridge, UK: BirdLife International.

Burnham, K. P., \& Anderson, D. R. (2002). Model selection and multimodel inference: A practical information-theoretic approach. New York: Springer.

Bystrak, D. (1981). The North American Breeding Bird Survey. Studies in Avian Biology, 6 , 34-41.

Carlisle, J. D., Kaltenecker, G. S., \& Swanson, D. L. (2005). Molt strategies and age differences in migration timing among autumn landbird migrants in southwestern Idaho. Auk, 122, 1070-1085.

Clobert, J., Le Galliard, J. F., Cote, J., Meylan, S., \& Massot, M. (2009). Informed dispersal, heterogeneity in animal dispersal syndromes and the dynamics of spatially structured populations. Ecology Letters, 12, 197-209.

Courchamp, F., Chapuis, J. L., \& Pascal, M. (2003). Mammal invaders on islands: Impact, control and control impact. Biological Reviews, 78, 347-383.

Dakhore, K. K., Bhattacharya, B. K., Mallick, K., Nigam, R., Patel, N. K., Pandey, V., et al. (2008). Energy budget over semi-arid agro-ecosystem using satellite data. Journal of Agrometeorology, 10, 58-64.

Daly, C., Gibson, W. P., Taylor, G. H., Johnson, G. L., \& Pasteris, P. (2002). A knowledgebased approach to the statistical mapping of climate. Climate Research, 22, 99-113.

D'Antonio, C. M., \& Vitousek, P. M. (1992). Biological invasions by exotic grasses, the grass/fire cycle, and global change. Annual Review of Ecology and Systematics, 23, $63-87$.

Diffenbaugh, N. S., Giorgi, F., \& Pal, J. S. (2008). Climate change hotspots in the United States. Geophysical Research Letters, 35, L16709.

Doligez, B., Part, T., \& Danchin, E. (2004). Prospecting in the collared flycatcher: Gathering public information for future breeding habitat selection? Animal Behaviour, 67, 457-466.

Fahrig, L. (2003). Effects of habitat fragmentation on biodiversity. Annual Review of Ecology Evolution and Systematics, 34, 487-515.

Filleul, L., Cassadou, S., Medina, S., Fabres, P., Lefranc, A., Eilstein, D., et al. (2006). The relation between temperature, ozone, and mortality in nine French cities during the heat wave of 2003. Environmental Health Perspectives, 114, 1344-1347.

Finlayson, H. H. (1932). Heat in the interior of South Australia: Holocaust of bird-life. South Australian Ornithologist, 11, 158-160.

Gordon, G., Brown, A. S., \& Pulsford, T. (1988). A koala (Phasocolarctos-conereus Goldfuss) population crash during drought and heat-wave conditions in Southwestern Queensland. Australian Journal of Ecology, 13, 451-461.

Guthery, F. S., Land, C. L., \& Hall, B. W. (2001). Heat loads on reproducing bobwhites in the semiarid subtropics. Journal of Wildlife Management, 65, 111-117.

Guthery, F. S., Rybak, A. R., Fuhlendorf, S. D., Hiller, T. L., Smith, S. G., Puckett, W. H., et al. (2005). Aspects of the thermal ecology of bobwhites in north Texas. Wildlife Monographs, 1-36.

Herkert, J. R. (1995). Analysis of midwestern breeding bird population trends - 19661993. American Midland Naturalist, 134, 41-50.

Hijmans, R. J., Cameron, S. E., Parra, J. L., Jones, P. G., \& Jarvis, A. (2005). Very high resolution interpolated climate surfaces for global land areas. International Journal of Climatology, 25, 1965-1978.

Hutchings, J. A. (2000). Collapse and recovery of marine fishes. Nature, 406, 882-885.

IPCC (2007). Climate Change 2007: Synthesis Report. In Core Writing Team, R. K. Pachauri, \& A. Reisinger (Eds.), Geneva, Switzerland: Intergovernmental Panel on Climate Change.

Jiguet, F., Julliard, R., Thomas, C. D., Dehorter, O., Newson, S. E., \& Couvet, D. (2006). Thermal range predicts bird population resilience to extreme high temperatures. Ecology Letters, 9, 1321-1330.

Link, W. A., \& Sauer, J. R. (1997). New approaches to the analysis of population trends in land birds: Comment. Ecology, 78, 2632-2634.

Lusk, J. J., Guthery, F. S., \& DeMaso, S. J. (2001). Northern bobwhite (Colinus virginianus) abundance in relation to yearly weather and long-term climate patterns. Ecological Modelling, 146, 3-15.

McKechnie, A. E., \& Wolf, B. O. (2010). Climate change increases the likelihood of catastrophic avian mortality events during extreme heat waves. Biology Letters, 6 , $253-256$.

McNab, B. K. (1970). Body weight and energetics of temperature regulation. Journal of Experimental Biology, 53, 329-348.

Meehl, G. A., \& Tebaldi, C. (2004). More intense, more frequent, and longer lasting heat waves in the 21st century. Science, 305, 994-997.

Merila, J., \& Svensson, E. (1997). Are fat reserves in migratory birds affected by condition in early life? Journal of Avian Biology, 28, 279-286.

Mildrexler, D. J., Zhao, M. S., Heinsch, F. A., \& Running, S. W. (2007). A new satellitebased methodology for continental-scale disturbance detection. Ecological Applications, 17, 235-250.
Mooij, W. M., Bennetts, R. E., Kitchens, W. M., \& DeAngelis, D. L. (2002). Exploring the effect of drought extent and interval on the Florida snail kite: Interplay between spatial and temporal scales. Ecological Modelling, 149, 25-39.

Murray, B. G. (1966). Migration of age and sex classes of passerines on Atlantic coast in autumn. Auk, 83, 352-360.

North American Bird Conservation Initiative - U.S. Committee (2009). The State of the Birds, United States of America. In (p. 36). Washington, D.C.: U.S. Department of Interior.

Novacek, M. J., \& Cleland, E. E. (2001). The current biodiversity extinction event: Scenarios for mitigation and recovery. Proceedings of the National Academy of Sciences of the United States of America, 98, 5466-5470.

Paradis, E., Baillie, S. R., Sutherland, W. J., \& Gregory, R. D. (1998). Patterns of natal and breeding dispersal in birds. Journal of Animal Ecology, 67, 518-536.

Parmesan, C., Root, T. L., \& Willig, M. R. (2000). Impacts of extreme weather and climate on terrestrial biota. Bulletin of the American Meteorological Society, 81, 443-450.

Parmesan, C., \& Yohe, G. (2003). A globally coherent fingerprint of climate change impacts across natural systems. Nature, 421, 37-42.

Pidgeon, A. M., Radeloff, V. C., Flather, C. H., Lepczyk, C. A., Clayton, M. K., Hawbaker, T. J., et al. (2007). Associations of forest bird species richness with housing and landscape patterns across the USA. Ecological Applications, 17, 1989-2010.

Pinheiro, J., Bates, D., DebRoy, S., \& Sarkar, D.R core team. (2007). nlme: Linear and nonlinear mixed effects models. $R$ package version 2.1-83.

PRISM Climate Group (2009). 4-km monthly products. In Corvallis, OR, USA: Oregon State University.

Rappole, J. H. (1995). The ecology of migrant birds. Washington, D.C.: Smithsonian Institute Press.

R Development Core Team (2010). R: A language and environment for statistical computing. In Vienna, Austria: R Foundation for Statistical Computing.

Reed, J. M., Boulinier, T., Danchin, E., \& Oring, L. W. (1999). Informed dispersal: Prospecting by birds for breeding sites. Current Ornithology, 15, 189-259.

Rich, T. D., Beardmore, C. J., Berlanga, H., Blancher, P. J., Bradstreet, M. S. W., Butcher, G. S., et al. (2004). Partners in Flight North American Landbird Conservation Plan. In (p. 84). Ithica, NY: Cornell Lab of Ornithology.

Rittenhouse, C. D., Pidgeon, A. M., Albright, T. P., Culbert, P. D., Clayton, M. K., Flather C. H., et al. (2010). Conservation of forest birds: Evidence of a shifting baseline in community structure. PLoS One, 5(8).

Rogers, C. M., \& Smith, J. N. M. (1993). Life-history theory in the nonbreeding period Trade-offs in avian fat reserves. Ecology, 74, 419-426.

Sauer, J. R., Link, W. A., \& Royle, J. A. (2004). Estimating population trends with a linear model: Technical comments. Condor, 106, 435-440.

Sauer, J. R., Peterjohn, B. G., \& Link, W. A. (1994). Observer differences in the North American Breeding Bird Survey. Auk, 111, 50-62.

Sekercioglu, C. H. (2006). Increasing awareness of avian ecological function. Trends in Ecology \& Evolution, 21, 464-471.

Sillett, T. S., \& Holmes, R. T. (2002). Variation in survivorship of a migratory songbird throughout its annual cycle. Journal of Animal Ecology, 71, 296-308.

Sutherland, G. D., Harestad, A. S., Price, K., \& Lertzman, K. P. (2000). Scaling of natal dispersal distances in terrestrial birds and mammals. Conservation Ecology, 4, 1-56.

Trenberth, K. E., \& Shea, D. J. (2005). Relationships between precipitation and surface temperature. Geophysical Research Letters, 32.

Turner, W., Spector, S., Gardiner, N., Fladeland, M., Sterling, E., \& Steininger, M. (2003). Remote sensing for biodiversity science and conservation. Trends in Ecology $\mathcal{E}$ Evolution, 18, 306-314.

USGS (2008). North American Breeding Bird Survey. In US Geological Survey Patuxent Wildlife Research Center.

Wan, Z. M. (2008). New refinements and validation of the MODIS land-surface temperature/emissivity products. Remote Sensing of Environment, 112, 59-74.

Wan, Z. M., \& Dozier, J. (1996). A generalized split-window algorithm for retrieving land-surface temperature from space. IEEE Transactions on Geoscience and Remote Sensing, 34, 892-905.

Wan, Z., \& Li, Z. L. (2008). Radiance-based validation of the V5 MODIS land-surface temperature product. International Journal of Remote Sensing, 29, 5373-5395.

Wan, Z. M., \& Li, Z. L. (1997). A physics-based algorithm for retrieving land-surface emissivity and temperature from EOS/MODIS data. IEEE Transactions on Geoscience and Remote Sensing, 35, 980-996.

Wan, Z. M., Zhang, Y. L., Zhang, Q. C., \& Li, Z. L. (2003). Validation of the land-surface temperature products retrieved from Terra Moderate Resolution Imaging Spectroradiometer data. Remote Sensing of Environment, 83, 163-180.

Weathers, W. W. (1997). Energetics and thermoregulation by small passerines of the humid, lowland tropics. Auk, 114, 341-353.

Yarbrough, C. G. (1971). Influence of distribution and ecology on thermoregulation of small birds. Comparative Biochemistry and Physiology, 39, 235-266.

Zaitchik, B. F., Macalady, A. K., Bonneau, L. R., \& Smith, R. B. (2006). Europe's 2003 heat wave: A satellite view of impacts and land-atmosphere feedbacks. International Journal of Climatology, 26, 743-769. 